\title{
Un inventario de enigmas: la prosa reflexiva de Julio Ramón Ribeyro
}

\section{Carlos López Degregori}

El otorgamiento en 1994 del importante premio internacional "Juan Rulfo" a Julio Ramón Ribeyro, poco antes de que falleciera, significó el reconocimiento en el ámbito de nuestra lengua de la trascendencia y el valor de una de las más notables aventuras literarias en la cultura peruana de la segunda mitad de este siglo. Esta importancia se acrecienta aún más si tomamos en cuenta que, en el contexto de la denominada "Generación del Cincuenta", Ribeyro es un autor que ha desplegado su obra en múltiples direcciones y explorando con exigencia e inusual calidad el relato de ficción breve, la novela, el teatro, la confesión autobiográfica, el ensayo, la crítica literaria y el texto de meditación existencial ética y estética.

Sin embargo, este destino polimorfo de su obra no ha sido valorado con igual interés por la crítica y los asiduos lectores de sus ficciones. En efecto, si bien existe un consenso y todos reconocen la trascendencia de su obra narrativa - sin muchas discusiones puede afirmarse que Ribeyro es el más importante cuentista peruano y una de las figuras capitales del relato corto latinoamericano- su obra crítica y reflexiva ha sido leída, en cambio, como secundaria 
y tangencial. Las siguientes páginas quieren dejar de lado al autor de ficciones y revisar desde una perspectiva muy general la prosa reflexiva de Ribeyro contenida en tres de sus libros: La caza sutil, Prosas apátridas y Dichos de Luder. Reconocemos, por supuesto, que el discurso reflexivo del autor de La palabra del mudo no es un ejercicio riguroso de crítica literaria ni pretende tampoco configurar un sistema ético y estético que llame la atención por su originalidad; por el contrario, los breves ensayos y artículos literarios de La caza sutil y los textos inclasificables de Prosas apátridas y Dichos de Luder operan como una mirada continua y soterrada que aspira a convertirse en testimonio y problematización de un destino escritural. De otro lado, la prosa reflexiva de Ribeyro -interesándose igualmente por los problemas estéticos y existenciales- renuncia intencionalmente a la sistematización para hallar en el microensayo, el apunte iluminador, y el fragmento marginal e inconexo su razón de ser y coherencia. No es gratuito, por ello, que el autor haya elegido el título de Prosas apátridas para identificar su libro reflexivo más importante; esta denominación refuerza una desconfianza radical ante los cánones y géneros que le otorgan seguridades a la literatura y, sobre todo, a la tarea conscientemente ejercida de desautorizar una voz - la suya propia - minando las certezas del escritor consagrado y dueño de su destino. Quizá estos tres libros extraños en la producción literaria de Ribeyro sean la sincera biografía de un autor que convirtió el laconismo, la duda sonriente y la modestia en su manera cabal de estar en el mundo.

\section{I}

La caza sutil reúne veintiún breves ensayos y artículos de crítica literaria de diversa temática e interés escritos entre 1953 y 1965. Casi todos ellos habían sido publicados previamente en el suplemento $E l$ Dominical del diario El Comercio, la revista Amaru o fueron prólogos y epílogos a libros de otros autores; se incluyen, además, dos conferencias dictadas respectivamente en la Biblioteca Nacional en agosto de 1971 y en el Instituto Nacional de Cultura en 1973.

1 Para una noticia acerca de la primera edición de estos artículos consúltese la bibliografía que ofrecemos al final de este trabajo. 
Es interesante observar que la aparición de La caza sutil se da en un periodo especialmente prolífico de la producción de Ribeyro. Dos años antes Milla Batres había dado a conocer la primera edición de La palabra del mudo y el mismo año de 1975 era publicada en Barcelona la primera edición de Prosas apátridas. Las explicaciones para esta fertilidad editorial son múltiples. Cabe reconocer una "oportunidad" de acceder a la letra impresa vinculada al reconocimiento nacional de un autor que había trabajado sin pausa sus ficciones desde los años cincuenta; pero también podría intervenir una necesidad de afirmación vital después de una crítica enfermedad que puso a Ribeyro al borde de la muerte en 1973.

Con relación a la aquiescencia del autor para reunir sus artículos desperdigados en diversas publicaciones periódicas -y sin desconocer las razones antes mencionadas - intervendría, también, una motivación de índole metaliteraria. Ribeyro califica - en la contratapa del libro- a sus artículos de "impresionistas", "circunstanciales" y "marcados por el sello de lo contingente", y cualquier lector no puede evitar preguntarse por el valor y justificación de un libro de tan modestos propósitos. Por ello, es indispensable entender que el real acceso a estos textos supone no abordarlos como trabajos rigurosos de crítica literaria, sino como el camino paralelo que recorre un narrador para consolidar una actitud y convicciones literarias. Probablemente Ribeyro quiso recuperar a través de ese "desaprensivo paseo entre libros y autores" sus contactos con la literatura, su experiencia europea, sus relaciones con el Perú y el esclarecimiento de su proceso creativo. Si todo discurso crítico lleva las "marcas" de su productor, este rasgo se torna decisivo en el caso de los creadores en los que el texto dice más del creador que de los ocasionales autores por los que se preocupa. Ya ha señalado Benveniste, por ejemplo, que el sujeto productor del discurso es una entidad que no puede disociarse de su práctica discursiva en tanto el "acto individual de apropiación de la lengua introduce al que habla en su habla". Así el discurso se presenta no solo atravesado de subjetividad sino que es el lugar en donde el sujeto productor del texto se construye a sí mismo. Si esta aproximación es válida para cualquier utilización del lenguaje, cobra un relieve especial en el ámbito del ensayo y la crítica literaria que busca separarse de la asepsia académica y la investigación y se proclama a sí misma como parcial y subjetiva. Acercarse a los textos reflexivos de La caza sutil supone, pues, descubrir en ellos 
una actitud empática ante el fenómeno literario y la práctica -consciente o no- en la que el productor va decantando sus convicciones, juicios y valores para hacerse y reconocerse escritor. No está de más precisar que la redacción primera de estos trabajos - el más antiguo se remonta a 1953- propone un diálogo implícito pero permanente con las sucesivas obras de ficción que nuestro autor da a conocer hasta el año 1973, y que con la publicación de sus cuentos reunidos merecían el rescate para ofrecer al fin sus relaciones ocultas y coherencia.

Este sesgo subjetivo de los artículos reunidos en este libro se condice, por último, con la especial predilección que el autor ha mostrado siempre por el diario íntimo y la escritura confesional. Anular, en lo posible, las diferencias entre el mundo ilusorio de la literatura y la propia existencia ha sido el interés constante de Ribeyro y este designio se percibe también en su obra crítica.

Pero qué es para Ribeyro la crítica literaria. En el artículo dedicado al gran crítico Ernest Robert Curtius, escrito en 1953 -es decir cuando nuestro autor daba a conocer sus primeros textos reflexivosseñala que es "la forma de literatura cuyo objeto es la literatura misma" (CZ: "Ernest Robert Curtius y la literatura francesa", p. 33)². Quince años más tarde - en 1968 - en una nota que aparecería como epílogo a un libro de Wolfgang A. Luchting reitera esta opinión añadiéndole un matiz irónico y un sesgo más personal:

La crítica literaria es un género ante el que siento cada vez más perplejidad e incluso irritación. Lo que más me sorprende en ella es su carácter parasitario, el hecho de que no pueda existir independientemente de los textos ajenos. Literatura sobre literatura se le llamó hace una treintena de años. Ahora los estructuralistas le han dado el nombre más imponente de metaliteratura. Al apelativo de parasitario habría que añadirle el de canceroso, por su tendencia a reproducirse ilimitadamente a partir de un texto original que se critica. (CZ: “Epílogo a pasos a desnivel", p. 57.)

2 Para las citas optaremos por las siguientes siglas: CZ: La caza sutil (Lima: Editorial Milla Batres, 1976); PA: Prosas apátridas (existen tres ediciones y cada una de ellas incorpora nuevos textos; aquí recurriremos a la tercera edición: Lima: Cofide/Milla Batres, 1992); DL: Dichos de Luder (Lima: Jaime Campodónico editor, 1989). 
Si bien en ambos casos se subraya el carácter secundario del discurso crítico, interesa sobre todo dilucidar qué hace de cierta crítica una propuesta valiosa alejándola de la mera proliferación de juicios y palabras que terminan empañando su propio objeto de estudio.

La respuesta la ofrece Ribeyro en el propio quehacer de Curtius que transforma esa reflexión secundaria en una tarea "creadora, interpretativa y valorativa" (CZ: "Ernest Robert Curtius y la literatura francesa", p. 33). La crítica deja así su carácter dependiente y precario para ser un acercamiento empático a los textos que aborda, y que al nutrirse de una suerte de pasión se trasforma en literatura.

No está lejos Ribeyro de una sugerente propuesta de Barthes que reconoce en el placer el verdadero estatus de la lectura. Es posible, señala Barthes, reconocer tres tipos de placer de lectura o "tres vías por las que la Imagen de lectura puede aprisionar al sujeto leyente".

El primer tipo plantea una relación "fetichista con el texto leído", extrayendo placer de la misma materialidad de las palabras y de las combinaciones que producen; el segundo tipo está marcado por el "orden del suspenso" y la fuerza que atrae al lector para seguir adelante y desvelar lo que el texto esconde; el último placer es el de la "Escritura", la lectura como buena "conductora del deseo de escribir". La lectura así planteada, concluye Barthes, se transforma en "producción: ya no de imágenes interiores, de proyecciones, de fantasmas, sino, literalmente, de trabajo", en tanto el producto consumido se convierte en producción ${ }^{3}$.

El crítico es, pues, y en esto parece coincidir Ribeyro con Barthes, quien hace suyo ese llamado a escribir, dejando de ser solo un intérprete o un mediador para entregar su propia creación. Esto no significa, por supuesto, el mero impresionismo o arbitrariedad, pues el quehacer crítico debe sustentarse en una "estética coherente" o centro de gravedad que ofrece un "conjunto de principios, convicciones y certezas sobre lo que es la literatura" (CZ: "Epílogo a pasos a desnivel", p. 59). Los juicios del crítico, entonces, sin renunciar a su cualidad creativa y a la personalidad y pasión involucradas, serán

3 Barthes, Roland. "Sobre la lectura". El susurro del lenguaje. Más allá de la palabra y la escritura, 1987, pp. 39-49. Consúltese también: El placer del texto. 
válidos en tanto remitan a ese centro de gravedad y encuentren en él su justificación. No es de extrañar, pues, que para la mirada de nuestro autor la verdadera crítica se aleje por igual de la aburrida erudición de los trabajos académicos y de la pasajera actividad halagadora o denostativa que suele acompañar las reseñas y comentarios de los diarios. Es, por cierto, esta crítica la que Ribeyro halla en el Perú en los años cincuenta y sesenta y su opinión al respecto es enfática:

En un país como el Perú donde la crítica - con pocas excepciones- ha sido siempre ejercida por profesores pesados o por periodistas ligeros, es saludable ver un grupo de ensayos que no son obra de un erudito ni de un gacetillero sino de un hombre de formación literaria seria, un hombre perspicaz, inteligente, independiente, que ama su oficio y que posee una punta de humor [...]. (CZ: "Epílogo a Pasos a desnivel”, p. 58.)

Los juicios citados, que el importante narrador peruano le regala a Luchting, no dejan de sonar como una justificación. Hay, por último, una cualidad adicional que parece cautivar a Ribeyro: la asistematización. Luchting - desconfiando de las escuelas estilística, estructuralista, genética, marxista, freudiana, etcétera- se presenta como un escéptico ante la crítica literaria y por ello mismo un ecléctico. Este carácter errante y asistemático, que contempla con igual horror las seguridades del teórico o la inconsistencia del gacetillero, es el que a fin de cuentas alimenta todos los textos críticos del autor de La palabra del mudo y entrega las coordenadas para su correcta lectura ${ }^{4}$.

Los focos de atención de estos veintidós textos son, por supuesto, diversos. "Peruanos en París" desenmascara en clave irónica un cierto modo de ser de los peruanos en el marco eu-ropeo; mientras que "Las discusiones" y "El amor a los libros" exploran una actitud intelectual.

4 En relación con la crítica literaria en el Perú es interesante observar los juicios que le dedica Ribeyro a la recepción de la novela de Luis Felipe Angell La tierra prometida (CZ: "Crítica literaria y novela", pp. 63-66). Allí declara enfáticamente que la crítica literaria no existe en el Perú, "Cuando más, algún amigo o colega del autor, hace una reseña de compromiso en la cual, por un pudor muy comprensible ni se ataca ni se elogia“. Igualmente, Ribeyro se opone a juzgar "el valor de una obra literaria de acuerdo con la dicotomía verdad-error", según pueda o no una obra - desde una perspectiva meramente sociológica - reflejar la realidad con exactitud. 
Sin embargo, varias de las incursiones de esta "caza" quieren dar cuenta de autores $\mathrm{u}$ obras que en algún momento llamaron su atención de lector (tal es el caso de "Gustavo Flaubert y el bovarismo", "El caso Françoise Sagan", "Flaubert y la presunta peruana" o "Carta de París. Adamov y el teatro político"); la preocupación por la literatura peruana ("Lima ciudad sin novela", "Los ríos profundos, José María Arguedas o la destrucción de la Arcadia" y "Chariarse o el vate vagante") y, también, latinoamericana ("Algunas digresiones en torno a El otoño del patriarca"). Otros trabajos se interesan por la naturaleza de la ficción y las técnicas narrativas ("Problemas del novelista actual", "Las alternativas del novelista", "Del espejo de Stendhal al espejo de Proust"); por la crítica literaria ("Crítica literaria y novela", "Ernest Robert Curtius y la literatura francesa" y "Epílogo a Pasos a desnivel"); la escritura confesional y los diarios personales ("En torno a los diarios íntimos", "Dos diaristas peruanos"); sin excluir la visión de la propia obra ("Prólogo a la tesis de Marc Vaille-Angles"). Es probable que si no existiera el respaldo de la obra narrativa de Ribeyro estos trabajos se limitarían a ser un índice de los problemas que obsesionaban a la reflexión literaria en el Perú en las décadas del cincuenta y sesenta. Su valor, sin embargo, es hoy diferente y ellos ofrecen un apreciable material para todos los que deseen explorar la "poética" de su autor e incluso las obsesiones de la narrativa peruana y latinoamericana en esas fechas. Las puertas quedan, pues, abiertas.

\section{II}

Si los escritos de La caza sutil mantienen un relativo distanciamiento del yo - a pesar de la subjetividad que ya hemos señalado- en el ámbito de la escritura reflexiva de Julio Ramón Ribeyro, las Prosas apátridas, en cambio, solo existen para que el yo productor (prescindiendo de las mediaciones de su ficción y de la parcial objetividad del análisis crítico que de alguna manera lo otrifican) declare sus perplejidades, ironías y temores a un oyente que, sin ignorar la participación cómplice del lector, es él mismo.

No es errado, por ello, adentrarse en estos textos como quien se sumerge en las estancias de un monólogo o espía las páginas privadas 
de un diario personal $1^{5}$, del que se han salvado fragmentos "sin destino ni función precisa". Este carácter confidencial y esta ausencia de finalidad aparente dice mucho de las prosas: su objetivo no es persuadir y menos ofrecer una visión unificadora y coherente de la realidad, la existencia y la creación artística; y estará descaminado el lector que pretenda extraer de ellas un programa de acción: "Nada me incomoda más que ser tomado alguna vez [...] como modelo de cualquier cosa" -afirma Ribeyro-, “detesto los consejos y los paradigmas" (PA 134).

Las Prosas apátridas son, en esta perspectiva, las confesiones de un observador - testigo (en el que la participación del autor queda casi excluida) o los subterfugios para aplacar la ansiedad que la misma existencia provoca. Los lectores debemos, entonces, aceptarlas como una vivencia ajena que nos es ofrecida, y que al contrastarla con lo que somos en un ejercicio de conciencia, bien puede no hacernos mejores pero sí contribuir a mirarnos sin concesiones y finalmente aceptarnos.

Desde un punto de vista formal, y como ya han señalado los mejores intérpretes de este libro ${ }^{6}$, su expresión halla en el microensayo

5 Es significativo que en un artículo de 1953 sostenga Ribeyro, refiriéndose a los diarios íntimos, que ellos se caracterizan por la "libertad de composición", por aceptar "todos los tonos y estilos", por su "sentido del fragmento" y por la sensación de ser "obras inconclusas" (CZ: "En torno a los diarios íntimos", p. 11). Estos rasgos pueden trasladarse sin ninguna dificultad al libro que estamos comentando. De otro lado, la estructura abierta - como en un monólogo sin fin- es reforzada por las sucesivas incorporaciones de nuevos fragmentos en las distintas ediciones (89, 150 y 200 prosas, respectivamente). Este libro, en teoría, bien podría crecer indefinidamente. Por cierto, Vargas Llosa en su artículo "Ribeyro y las sirenas" subraya que leer este libro "es recibir una confesión impúdica" pero no en un sentido anecdótico ni chismográfico, sino intelectual y moral" (Vargas Llosa, Mario. "Ribeyro y las sirenas". Contra viento y marea, 1990).

6 El lector puede revisar los trabajos de Mario Vargas Llosa "Ribeyro y las sirenas" y de Luis Jaime Cisneros "Prosas clásicas"; si bien estos textos aparecieron originalmente en distintas publicaciones, se encuentran recogidos en el volumen colectivo Asedios a Julio Ramón Ribeyro (1996). También puede consultarse "Ribeyro o el escepticismo como una de las bellas artes", prólogo de José Miguel Oviedo a la primera edición de este libro (1975). 
la confesión abierta, el apunte y el fragmento marginal e inconexo, su razón de ser que instaura una "incoherente coherencia"7.

Vale aquí la pena atender la sugerencia de Alberto Escobar, que halla en la Prosa 149 la exacta definición de cada uno de sus fragmentos y "la descripción del libro que los ordena":

Imaginar un libro que sea desde la primera hasta la última página un manual de sabiduría, una fuente de regocijo, una caja de sorpresas, un modelo de elegancia, un tesoro de experiencias, una guía de conducta, un modelo para los estetas, un enigma para los críticos, un consuelo para los desdichados y un arma para los impacientes. ¿Por qué no escribirlo? Sí, pero ¿cómo y para qué? (PA 149.)

El libro reclamado no es otro que Prosas apátridas, y la ausencia de centro que el carácter heteróclito de sus textos sugiere, le permite ser simultáneamente sabiduría, regocijo, sorpresa, enigma y modelo de conducta.

Sin embargo, este designio multiforme de sus componentes encuentra su afinidad en el desencanto y el escepticismo de Julio Ramón Ribeyro, que se convierte después de una lectura sostenida en la única sabiduría que puede, con lucidez y honestidad, entregarse ${ }^{9}$.

7 Vargas Llosa sostiene, por ejemplo, que es un libro "compuesto sin designio preciso, al correr de los años, en momentos de entusiasmo y desesperación, al sesgo de su trabajo de narrador, tiene de diario secreto y de libro de aforismos, de ensayo filosófico y borrador de ficciones, de poesía y tratado moral"; para añadir luego que su lectura deja la "sensación de entrar a una confesión impúdica" ("Ribeyro y las sirenas").

8 Escobar, Alberto. "La palabra indirecta de las Prosas apátridas". En pocas palabras, 1996, pp. 58-76.

9 Al respecto Susana Reiz propone una lectura de Ribeyro desde las claves de la posmodernidad: "La maldición de la duda - o la la falta de fe en la postmodernidad, como prefieren llamarla otros menos sentimentales que Ribeyro- es el signo de nuestro tiempo, en el que los libros sagrados no existen ya o se suceden con demasiada rapidez. Como en la tardía antigüedad la época no es muy sensible a las teogonías, ni a las grandes epopeyas, ni a los frescos monumentales de la sociedad, ni a los extremos de pasión de la tragedia. Es el momento ideal para el florecimiento de los géneros menores 
El escepticismo de este libro se torna así radical, como ha subrayado Oviedo ${ }^{10}$ y "cuando parece atenuarse es para mostrar que hay flancos en la realidad que todavía tratan de seducir, por unos instantes, a los incautos"; tal es su finalidad, opacar esas seducciones; y aunque el libro pueda dejarnos inermes, su negatividad es positiva, "es inteligente, es serena, es de una nobleza que se confunde muy bien con la sabiduría".

Si toda clasificación es arbitraria y no puede en rigor aprehender la pluralidad y los matices de lo que se observa, este afán ordenador es aún más espinoso en un libro que quiere ser al mismo tiempo tantas cosas diferentes y ninguna. No obstante, y sin ánimo de ser exhaustivos, estas prosas heteróclitas giran en torno a unas cuantas obsesiones: la condición humana con sus parcelas de amor, amistad, desesperación, tiempo y muerte; la literatura y la expresión artística; y el desenmascaramiento de nuestros ritos, pequeños vicios y comportamientos cotidianos. Su tratamiento es pasar de las abstracciones y generalidades intemporales a lo presente y concreto en un movimiento pendular, y los restos significativos que en su dinámica van surgiendo se comportan siempre como acercamientos o posibilidades, nunca como verdades inconmovibles. Bien puede reparar el lector en las palabras del campesino que aparece en la Prosa 122, cuando anuncia que El Paititi o El Dorado que buscán codiciosamente todos los aventureros jamás será encontrado.

(en formato o en disposición ideológica): para el relato pequeño, las notas, las memorias, los recuerdos íntimos, las reflexiones a media voz, las explicaciones parciales y parcializadas, el humor, la ironía, la parodia y la antiparodia. Estamos en una coyuntura histórica en la que el interés de los lectores se desplaza de las voces tonantes y admonitorias de vates y maestros al creciente murmullo de los marginales. "La hora de Ribeyro". Texto leído en las conferencias y mesas redondas programadas en Guadalajara a raíz de la obtención del Premio de Literatura Latinoamericana y del Caribe Juan Rulfo 1994; publicado posteriormente en Hueso Húmero 34, 1994.)

10 Oviedo, José Miguel. "Ribeyro o el escepticismo como una de las bellas artes". Abelardo Oquendo califica también a Ribeyro de "escéptico radical" y añade que en ninguna de sus prosas "se pregunta por las causas: las causas explican accidentes, no esencias. El cómo, el qué, van con Ribeyro; no el por qué". (Oquendo, Abelardo. Prólogo a Prosas apátridas aumentadas, 1978.) 
Algo similar plantea la Prosa 124: "Todo tiene importancia, nada tiene importancia, aquí, ahora". La paradoja y la sinrazón, nos recalca Ribeyro, son la única sabiduría: vivir en forma simultánea la duda y la seguridad, pisar la tierra firme y las arenas movedizas; el resultado no funciona, por supuesto, bajo los criterios de verdad-falsedad o aceptación-rechazo, y solo le resta al lector quedarse con perplejidades, veladuras, contradicciones.

La existencia como anécdota banal, desesperanza o viaje ciego y derrotado (PA 52) entre el nacimiento y la muerte que todos emprendemos con mayor o menor conciencia, es el centro de la visión ribeyreana. Casi podríamos elegir al azar cualquier fragmento de este libro para corroborarlo, pero probablemente tenga su enunciación más transparente en la Prosa 2:

Vivimos en un mundo ambiguo, las palabras no quieren decir nada, las ideas son cheques sin provisión, los valores carecen de valor, las personas son impenetrables, los hechos amasijos de contradicciones, la verdad una quimera y la realidad un fenómeno tan difuso que es difícil distinguirla del sueño, la fantasía o la alucinación. La duda, que es el signo de mi inteligencia, es también la tara más ominosa de mi carácter. Ella me ha hecho ver y no ver, actuar y no actuar, ha impedido en mí la formación de convicciones duraderas, ha matado hasta la pasión y me ha dado finalmente del mundo la imagen de un remolino donde se ahogan los fantasmas de los días, sin dejar otra cosa que briznas de sucesos locos y gesticulaciones sin causa ni finalidad. (PA 2.)

El desamparo que deja este texto en el ánimo del lector es absoluto y lo endurece para resistir las escépticas palabras que hallará en cada página. Sin embargo, el trayecto no es tan sencillo en su oscuridad: ante el escepticismo pueden contraponerse, desde luego, algunas ilusiones, pues aunque la mayor parte de nuestros actos son inútiles y aunque nuestra vida está "tejida con esa trama gris y sin relieve", siempre podemos aguardar la aparición repentina de "una flor, una figura" (PA 138). Esas flores y figuras, que tal vez otorguen alguna justificación oculta a nuestra existencia pueden manifestarse en la mujer que es vista como una "fuerza vital" ("una mujer cómo anima una casa") puliendo y embelleciendo todo lo que nos rodea (PA 16) o en el lento recorrido por el cuerpo amado (PA 5); en la amistad donde cada amigo es "dueño de una gaveta de nuestro ser" (PA 39); o en el dominio inocente de la infancia porque en ella no ha caído aún 
la "maldición de la duda" (PA 19) y es, con "nuestra casa", el mejor espacio de seguridad (PA 40). Incluso es posible fabricar, dudando de la duda misma, un deseado "esplendor" donde solo crezcan esas "flores y figuras":

Me despierto a veces minado por la duda y me digo que todo lo que he escrito es falso. La vida es hermosa, el amor un manantial de gozo, las palabras tan ciertas como las cosas, nuestro pensamiento diáfano, el mundo inteligible, lo que hagamos útil, la gran aventura del ser. Nada en consecuencia será desperdicio: el fusilado no murió en vano, valía la pena que el tenor cantara ese bolero, el crepúsculo fugaz enriqueció a un contemplativo, no perdió su tiempo el adolescente que escribió un soneto, no importa que el pintor no vendiera su cuadro, loado sea el curso que dictó el profesor de provincia, los manifestantes a quienes dispersó la policía transformaron el mundo, el guiso que me comí en el restaurant del pueblo es tan memorable como el teorema de Pitágoras, la catedral de Chartes no podrá ser destruida ni por su destrucción. (PA 150.)

Esta letanía invertida no puede anular, a pesar de los deseos y la imaginación, nuestra naturaleza banal y siempre propensa a la derrota: "[...] somos un instrumento dotado de muchas cuerdas, pero generalmente morimos sin que hayan sido pulsadas todas [...]. Dimos siempre la misma nota" (PA 97). El abismo que existe entre nuestras ilusiones y realidades es infranqueable y esa "única nota" que repetimos es, por supuesto, la de nuestra desesperanzada condición. Sin embargo, una confianza paradójica que niega el desánimo parece alentar en unos pocos fragmentos de este libro. Veamos, por ejemplo, la Prosa 118 que plasma esa ambivalencia:

Alguna divinidad, cuando nacemos, traza sobre nuestro nombre una cruz negra y entonces no habrá cuartel en nuestra vida, no encontraremos sino escollos, chanzas y ceadas y la más pequeña alegría tendremos que arrancarla a puro pulso, pujando, luchando contra la corriente, viendo en la ribera deslizarse a los afortunados, su carta triunfal en la mano, y sin permitirnos la menor distracción, pues solo se espera eso de nosotros que cedamos un instante al desánimo, para que el arma penetre hasta la empuñadura. (PA 118.)

El reconocimiento de una fatalidad que torna inútil cualquier lucha puede prestarse a fáciles conclusiones en las que solo cabe el pesimismo. El fragmento citado, no obstante, funciona a partir de la negación de una negación: la verdadera sabiduría está en actuar de 
una manera opuesta a la que se espera de nosotros evitando que el "arma" del escepticismo "penetre hasta la empuñadura", y ese ánimo exigido - en lucha contra la corriente para arrancar una mínima felicidad o sosiego - halla su mejor formulación en el texto que cierra el libro y que admite, desde luego, una lectura reconfortante:

La única manera de continuar en vida es manteniendo templada la cuerda de nuestro espíritu, tenso el arco, apuntando hacia el futuro. (PA 200.)

Nuestro trayecto bien puede ser banal y aferrado a esas "flores y figuras" que nos proponemos como falsas esperanzas, pero eso no invalida nuestro compromiso de seguir adelante. Existir, parece decirnos Ribeyro, es nuestra gran victoria.

\section{III}

La colección de los Dichos de Luder (1989) constituye una prolongación del discurso reflexivo inaugurado por las Prosas apátridas: la discusión acerca de la naturaleza del arte y la literatura, la presencia constante de la derrota y la precariedad, el aura banal de nuestras relaciones interpersonales y experiencias, aparecen nuevamente como los focos de interés primordiales en un apretado conjunto de mínimos fragmentos que son ofrecidos como los restos de "nuestra propia tiniebla interior" (DL 11) ${ }^{11}$. La novedad de estos textos radica, empero, en la estrategia discursiva que apuesta por la concisión del aforismo, el uso demoledor de la ironía y la incorporación de un plano ficticio que permite vincular la reflexión estricta - a la que nos había habituado el libro anterior - con el universo imaginario del relato.

11 Roberto Forns-Broggi, refiriéndose a la escritura fragmentaria de Ribeyro, anota que el fragmento “[...] niega la comodidad de encontrar un centro, un solo significado, una verdad dicha, tanto en las obras artísticas como en el mundo. Lo que hace es más bien devolver un sentido del potencial de cada momento, de cada palabra, de cada gesto y de cada evento, al mismo tiempo que reconocer la importancia radical del proceso de creación y expresión en la propia vida". ("Ribeyro y la función visual del fragmento: Notas en torno a Prosas apátridas y Dichos de Luder", en Márquez, I. y C. Ferreira (eds.). Asedios a Julio Ramón Ribeyro, 1996.) 
En efecto, la breve nota introductoria fechada en la ciudad de París, en 1984, funciona como el marco ficcional que extraña las propias palabras e ideas de Ribeyro para modularlas en una "otra voz" que exime al yo de gravedad y responsabilidades. El mismo nombre "Luder" nos evoca inmediatamente el término "ludismo" o "lúdico" y también al heterodoxo personaje "Ludo" de Los geniecillos dominicales, y no sería descaminado adentrarse en este libro como en una parodia que desmitifica la seriedad y tono sombrío de las Prosas apátridas a la par que la autoridad del creador formal y reconocido:

A Luder lo frecuenté mucho durante los largos años que vivió en París. Ocupaba un viejo departamento en el Barrio Latino sin más compañía que su criada y, por épocas, de una que otra amiga que podía quedarse allí sólo unos días o una larga temporada. En su espaciosa biblioteca, donde pasaba la mayor parte del tiempo leyendo, escribiendo o escuchando música - tan pronto óperas de Verdi como boleros de Agustín Lara- recibía al atardecer muy irregularmente a dos o tres amigos y a los pocos jóvenes autores o estudiantes que habían leído sus raras publicaciones. [...].

Con el tiempo estas veladas se fueron espaciando y llegó un momento en que Luder dejó de recibir y de salir [...]. Fue así que un día convocó a sus amigos más cercanos para anunciarnos que abandonaba París para instalarse en algún lugar del Perú [...]. Desde entonces, hace casi dos años, no hemos tenido noticias de él. Que se encuentre -como dicen algunos- en el valle del Urubamba, cerca del Cusco, amancebado con una campesina jovencísima y analfabeta o que haya elegido como refugio - según otros - una caleta pesquera abandonada es secundario y no viene al caso, pues no es mi propósito fomentar una pesquisa que atentaría contra su voluntad de apartamiento. Sólo quiero recalcar que la partida de Luder nos dejó una inquietud y, para ser sincero, una decepción. A pesar de la forma irónica como siempre se refirió a sus escritos y a la tarea literaria en general, sus amigos confiábamos que, llegado a la madurez, nos dejaría antes de partir algo más importante y sólido que los pocos libros que publicó en editoras marginales o a cuenta de autor. Quizás esta obra la esté escribiendo en su retiro ignorado, pero también es posible que su retiro sea una dimisión - una abdicación como él diría - de toda responsabilidad literaria. (DL, pp. 7-9.)

La presentación irónica que aquí se nos hace de Luder desmitificando el rol del creador y las aspiraciones literarias le otorgan una veracidad carnavalesca a sus palabras, y su "dimisión" es una renuncia a los cánones y grandezas de la Literatura. El discurso 
menor, la conversación deshilvanada o el murmullo que ensaya Luder en estos restos "sin protocolo ni concierto" son, por supuesto, los de un Julio Ramón Ribeyro aún más radical, que ha renunciado a la perfección formal de las Prosas y, que oculto tras la libertad de una máscara, lleva su escritura escéptica a la disolución. Probablemente sea uno de los últimos dichos de este delgado libro el que de una manera más cabal recoja el aliento de estos aforismos y el sentido todo del discurso reflexivo de Ribeyro: "Es penoso irse del mundo sin haber adquirido una sola certeza - dice Luder-. Todo mi esfuerzo se ha reducido a elaborar un inventario de enigmas" (DL, p. 43).

\section{IV}

No queremos finalizar estas páginas sin explorar un aspecto central en la producción de Ribeyro: la convicción de que la literatura es depositaria de la existencia. Probablemente así podamos valorar el aliento autobiográfico que mora en estos libros (sea una confesión cultural, ética o existencial). Si se revisa la producción narrativa de Julio Ramón Ribeyro pueden detectarse con claridad dos grandes ciclos que no se presentan como una ruptura sino como el diferente interés que le confiere el autor a la exploración de la sociedad peruana o a la indagación existencial. En este sentido el año de 1964 es crucial y el libro Tres historias sublevantes debe leerse como la síntesis de un recorrido por los laberintos de una sociedad y una ciudad, iniciado con Los gallinazos sin plumas (1955), y enriquecido con Cuentos de circunstancias (1958) y Las botellas y los hombres (1964). A este ciclo se refiere Ribeyro en el "Prólogo a la tesis de Marc Vaille-Angles" cuando puntualiza que sus cuentos constituyen "un intento de representación de la sociedad peruana" (CZ, p. 143); y sobre todo se hace evidente esta intención en las palabras que explican el título elegido para la reunión de sus piezas breves:

¿Por qué La palabra del mudo? Porque en la mayoría de mis cuentos se expresan aquellos que en la vida están privados de la palabra, los marginados, los olvidados, los condenados a una existencia sin sintonía y sin voz. Yo les he restituido ese hálito negado y les he permitido modular sus anhelos, sus arrebatos y sus angustias ${ }^{12}$.

12 La palabra del mudo, 1973, p. IX. 
La contextualización europea de Los cautivos (1972) y la visión de un Perú asumido como atmósfera de desencanto espiritual -antes que sociológico- de El próximo mes me nivelo (1972), La juventud en la otra ribera (1973), Silvio en El Rosedal (1977) o Sólo para fumadores (1987) son la decantación de un proceso que culmina en la recuperación de la propia memoria de los Relatos santacrucinos (1992).

El itinerario escritural de Ribeyro deviene, pues, de objetivo en subjetivo, de declaración colectiva y mirada urbana crítica en testimonio del yo que escribe para ofrecer su concepción de la existencia y sus recuerdos. No es casual, por ello, que en la introducción a $\mathrm{La}$ palabra del mudo de 1992 reoriente el sentido del título de su obra cuentística al de un "espejo" de la propia vida. La capacidad para captar la sociedad no queda excluida desde luego - los cuentos muestran "[...] oscuros habitantes limeños y sus ilusiones frustradas, escenas de la vida familiar, Miraflores, el mar y los arenales, combates perdidos, militares, borrachines, escritores, hacendados, matones y maleantes, locos, putas, profesores, burócratas, Tarma y Huamanga..." - pero ya no está presente el afán de proponer una visión "orgánica y coherente" de la realidad, pues esos relatos son únicamente los "fragmentos de mi vida y del mundo como lo vi"13. Esta declaración del privilegio de la propia mirada y de la construcción de la obra a partir de la existencia se complementa, por supuesto, con el constante interés y práctica que ha mostrado nuestro autor por el diario íntimo. Un diario, explica Ribeyro, "se funda en el principio de veracidad" (CZ: "En torno a los diarios íntimos", p. 10), veracidad que puede contrastarse al comparar sus páginas con los verdaderos hechos vividos;

13 Introducción a La palabra del mudo, 1994, pp. 7-8. Ribeyro es también enfático en la nota que abre el volumen IV de la edición de Milla Batres en 1992: “Una última observación, esta vez acerca del título general de mis cuentos. He mantenido el de La palabra del mudo, si bien sé que ya no corresponde enteramente a mi propósito original que era darle voz a los olvidados, los excluidos, los marginales, los privados de la posibilidad de expresarse. Y si lo he mantenido es porque dicho título ha cobrado para mí un nuevo significado. Quienes me conocen saben que soy un hombre parco, de pocas palabras, que sigue creyendo, con el apoyo de ciertos autores, en las virtudes del silencio. El mudo, en consecuencia, además de los personajes marginales de mis cuentos, soy yo mismo". 
ahora bien, si aceptamos que los relatos de La palabra del mudo son reclamados "espejo" de una existencia, no sería errado mirarlos -al lado de muchas otras lecturas, por supuesto- como la elaboración ficcional de una vida o la cifra oculta de la misma.

Esta inquietud aflora también en su crítica literaria y no es casual, por ello, que Ribeyro destaque la impronta confesional en los autores que ad mira. Ya en 1956, en su artículo dedicado a Flaubert, recuerda la conocida expresión del gran novelista - "Madame Bovary, soy yo"que desconcertó a los lectores de su tiempo, pero que demuestra la íntima correspondencia entre el creador y el personaje que inventa. La literatura de Flaubert, observa Ribeyro, "tiene un valor de confesión" (CZ: “Gustavo Flaubert y el bovarismo", p. 29) y, paradójica verdad para un novelista arquetipo del realismo y de la impersonalidad en la ficción, "su biografía se confunde con la composición de sus obras" (CZ, p. 30). El caso de Arguedas apunta también en la misma dirección y Ribeyro se acerca con empatía a Los ríos profundos por el amor "con que su autor escribe y describe"; y subraya que la postura de Arguedas ante los acontecimientos narrados "no es una actitud polémica ni protestante", pues "lo que lo ha movido a escribir no es tanto la indignación como la nostalgia", por ello Arguedas no ha escrito en rigor una "novela social" aunque deplore muchas de sus vivencias infantiles a las que ama en general "porque ellas han sido decisivas para la formación de su sensibilidad" (CZ: "Los ríos profundos", p. 69).

No es extraño, pues, que ya en los años setenta -con una concepción muy clara y decantada de la literatura- pueda Ribeyro sostener que escribir es "escrutar en nosotros mismos" (PA 55), o que la propia existencia viene al fin a convertirse en el único material literario en el que puede moverse con sinceridad un escritor:

No creo que para escribir sea necesario ir a buscar aventuras. La vida, nuestra vida, es la única, la más grande aventura. El empapelado de un muro que vimos en nuestra infancia, un árbol al atardecer, el vuelo de un pájaro, aquel rostro que nos sorprendió en el tranvía, pueden ser más importantes para nosotros que los grandes hechos del mundo. Quizás cuando hayamos olvidado una revolución, una epidemia o nuestros peores avatares, quede en nosotros el recuerdo del muro, del árbol, del pájaro, del rostro. Y si quedan, es porque algo los hacía memorables, algo había en ellos de imperecedero, y el arte sólo se alimenta de aquello que sigue vibrando en nuestra memoria. (PA 180.) 
La evidencia de esta Prosa es notable. Quizá solo debamos aclarar que la cita anterior pide mucho más que la sinceridad o el tratamiento ficticio de asuntos que tengan un sustento en la propia experiencia, si así sucediera Ribeyro se limitaría a mostrar la peripecia de un individuo; su intención, en cambio, es más sutil: pretende extraer de su banalidad y desamparo singulares, la banalidad y el desamparo que enraíza en todos los hombres, y con la mediación de la escritura convertirla en testimonio, justificación y destino. El yo no solo recobra su "aventura" personal $-\mathrm{y}$ la de la humanidad- en lo que escribe sino que, en el tramado de su obra, le otorga su verdadero sentido $y$, por decirlo de algún modo, logra que ella ocurra ${ }^{14}$. En la misma perspectiva, el acto creativo es asumido en otro de los fragmentos de este volumen, como un ejercicio de percepción privilegiado y es comparado con la ebriedad en tanto medio para extraviar la estructura y consistencia del entorno y hundirse en uno mismo:

La única manera que hay de comunicarme con el escritor que hay en mí es a través de la libación solitaria. Al cabo de unas copas él emerge. Y escucho su voz, una voz un poco monocorde, pero continua, por momentos imperiosa. Yo la registro y trato de retenerla, hasta que se va volviendo cada vez más borrosa, desordenada y termina por desaparecer cuando yo mismo me ahogo en un mar de náuseas, de tabaco y de bruma [...]. Hundido en mí como una semilla muerta, quizás recuerde las épocas felices en que cohabitábamos, más aún, en que éramos el mismo y no había distancia que salvar ni vino que beber para tenerlo constantemente presente. (PA 85.)

El fragmento anterior, siguiendo las coordenadas que aquí estamos proponiendo, no debe leerse como un simple llamado a la "inspiración" esquiva la mayoría de las veces o la declaración de las vicisitudes y dificultades inherentes a la tarea creativa; su reclamo se dirige, por el contrario, a la consecución de un estado libre de censura

14 La equivalencia vida-escritura es planteada igualmente con un guiño borgesiano al lector en otra de las Prosas: "Cada escritor tiene la cara de su obra" (PA 99). De otro lado, Susana Reisz destaca esa capacidad de Ribeyro para hablar en plural: "El éxito de Ribeyro - que en consonancia con las leyes de su universo narrativo, no llegó ni rápido ni fácilmente- se debe, pienso, a su excepcional empatía para registrar el sentir y la experiencia cotidiana del común de los mortales" ("La hora de Ribeyro"). 
en el que puedan coincidir el yo real del autor y el yo ficticio del texto. Vida y literatura terminan entonces confundiéndose y las páginas dejadas, por más insignificantes que sean, contienen "enhebrado el tiempo, mi (y nuestro, podríamos añadir) tiempo, la trama de mi (y nuestra) vida, que otros descifrarán como el dibujo en la alfombra" (PA 115). Probablemente no exista mejor rúbrica para el destino cotidiano y literario de Ribeyro que estas hermosas palabras de Luder: "No hay que buscar la palabra más justa, ni la palabra más bella, ni la palabra más rara. Busca solamente tu propia palabra" (DL, p. 43). Quisiéramos pensar que de haber caído Julio Ramón Ribeyro en la banalidad de regalarse un epitafio, habría elegido estas palabras.

\section{Bibliografía}

Barthes, R. (1987). "Sobre la lectura". El susurro del lenguaje. Más allá de la palabra y la escritura. Barcelona: Paidós.

Escobar, A. (1996). "La palabra indirecta en las Prosas apátridas". En pocas palabras. Lima: Instituto de Estudios Peruanos.

Márquez, I. y Ferreira, C. (eds.). (1996). Asedios a Julio Ramón Ribeyro. Lima: Pontificia Universidad Católica del Perú, Fondo Editorial.

Ribeyro, J. R. (1995). La tentación del fracaso. Diario personal. Tomo I: 19501960; tomo II: 1960-1974 (1993); tomo III: 1975-1978. Lima: Jaime Campodónico Editor/Cofide.

Ribeyro, J. R. (1992). La palabra del mudo. Cuentos 1952/1992. Vol. IV. Lima: Milla Batres. (Contiene las colecciones Relatos santacrucinos y Sólo para fumadores).

Ribeyro, J. R. (1992). Prosas apátridas aumentadas. Lima: Milla Batres. (Doscientos textos).

Ribeyro, J. R. (1989). Dichos de Luder. Lima: Jaime Campodónico Editor.

Ribeyro, J. R. (1987). Sólo para fumadores. Lima: El Barranco.

Ribeyro, J. R. (1978). Prosas apátridas aumentadas. Lima: Milla Batres. (Ciento cincuenta textos.)

Ribeyro, J. R. (1977). La palabra del mudo. Vol. III. Lima: Milla Batres. Contiene las colecciones Silvio en El Rosedal y La juventud en la otra ribera. 
Ribeyro, J. R. (1976). Cambio de guardia. Lima: Milla Batres, 1976.

Ribeyro, J. R. (1976). La caza sutil. Lima: Milla Batres.

Ribeyro, J. R. (1975). Prosas apátridas. Barcelona: Tusquets. (Ochenta y nueve textos.)

Ribeyro, J. R. (1975). Teatro. Lima: Instituto Nacional de Cultura.

Ribeyro, J. R. (1973). La palabra del mudo. Cuentos 1952/1972. Vols. I y II. Lima: Milla Batres. (Reúne los libros de cuentos editados hasta la fecha y las colecciones Los cautivos (1972) y El próximo mes me nivelo (1972).

Ribeyro, J. R. (1973). La juventud en la otra ribera. Lima: Mosca Azul Editores.

Ribeyro, J. R. (1965). Los geniecillos dominicales. Lima: Populibros Peruanos.

Ribeyro, J. R. (1964). Las botellas y los hombres. Lima: Populibros Peruanos.

Ribeyro, J. R. (1964). Tres historias sublevantes. Lima: Mejía Baca.

Ribeyro, J. R. (1960). Crónica de San Gabriel. Lima: Tawantisuyo.

Ribeyro, J. R. (1958). Cuentos de circunstancias. Lima: Nuevos Rumbos.

Ribeyro, J. R. (1955). Los gallinazos sin plumas. Lima: Círculo de Novelistas Peruanos.

Vargas Llosa, M. (1990). “Ribeyro y las sirenas". Contra viento y marea. Lima: Peisa. 